\title{
A Multilevel Analysis of the Impact of Land Use on Interannual Land-Cover Change in East Africa
}

\author{
S. Serneels, ${ }^{1}$ M. Linderman, ${ }^{2}$ and E. F. Lambin ${ }^{1, *}$ \\ ${ }^{1}$ Department of Geography, University of Louvain, 3, place Louis Pasteur, 1348 Louvain-la-Neuve, Belgium; ${ }^{2}$ Department of \\ Geography, University of Iowa, Iowa City, Iowa 52242, USA
}

\begin{abstract}
The aim of this study was to characterize the shortterm land-cover change processes that were detected in Eastern Africa, based on a set of change metrics that allow for the quantification of interannual changes in vegetation productivity, changes in vegetation phenology and a combination of both. We tested to what extent land use, fire activity and livestock grazing modified the vegetation response to short-term rainfall variability in East Africa and how this is reflected in change metrics derived from MODerate Imaging Spectrometer (MODIS) time series of remote sensing data. We used a hierarchical approach to disentangle the contribution of human activities and climate variability to the patterns of short-term vegetation change in East Africa at different levels of organization. Our results clearly show that land use significantly influences the vegetation response to rainfall variability as measured by time series of MODIS data. Areas with different types of land use
\end{abstract}

\section{INTRODUCTION}

Time series of satellite data have long been used to study land-cover changes at global to regional scales. One of the major challenges is to distinguish between changes linked to interannual climate variability and land-cover changes induced by anthropogenic processes. These climatic, geomor-

Received 21 April 2006; accepted 10 October 2006 *Corresponding author; e-mail: lambin@geog.ucl.ac.be react in a different way to interannual climate variability, leading to different values of the change indices depending on the land use type. The impact of land use is more reflected in interannual variability of vegetation productivity and overall change in the vegetation, whereas changes in phenology are mainly driven by climate variability and affect most vegetation types in similar ways. Our multilevel approach led to improved models and clearly demonstrated that climate influence plays at a different scale than land use, fire and herbivore grazing. It helped us to understand dynamics within and between biomes in the study area and investigate the relative importance of different factors influencing short-term variability in change indices at different scales.

Key words: MODIS; land use; multilevel model; East Africa; human impact; climate variability.

phic and anthropogenic processes interact in a complex and dynamic way, and lead to a wide range of ecosystem responses at different scales (Nicholson 2001). Both a quantification of the magnitude of change as well as a characterization of the change processes are required to unravel the driving forces of change and their effects on landcover dynamics (Vanacker and others 2005). Many studies have linked interannual variability in vegetation activity to climate variability such as rainfall anomalies and ENSO events (for example, Daven- 
port and Nicholson 1993; Anyamba and Eastman 1996; Eklundh 1998; Plisnier and others 2000; Vanacker and others 2005). However, little is known about the interactions between human land use and the short-term variability of vegetation activity at regional scales. Until now, the hierarchical organization of ecosystems, human activities, and their interactions at different levels, from the landscape to the region, has largely been ignored in remote sensing studies. Processes at these different levels are interdependent. Factors operating at one level of the hierarchy might influence processes at a higher or lower level, and should thus be analyzed simultaneously.

The aim of this study was to identify the human influence on short-term land-cover changes that were detected in Eastern Africa based on a set of change metrics that allow quantification of interannual changes in vegetation productivity, changes in vegetation phenology and a combination of both (Linderman and others 2005). Vanacker and others (2005) showed that several ecosystems in sub-Saharan Africa are highly sensitive to short-term rainfall variability. We tested to what extent land use, fire activity and livestock grazing modify the vegetation response to shortterm rainfall variability in East Africa and how this is reflected in the change metrics developed by Linderman and others (2005). We used landcover change metrics derived from 3 years of 1 $\mathrm{km}$ resolution, bidirectionally corrected reflectance values of MODerate Imaging Spectrometer (MODIS) data (2000-2003) (Schaaf and others 2002) in combination with data on rainfall, land use, fire activity, livestock density, human population density and conservation status of the land. We used a hierarchical approach to disentangle the contribution of human activities and climate variability to the patterns of short-term vegetation change in East Africa at different levels of ecosystem organization. The data were aggregated into units of similar pedomorphological characteristics (referred to as landforms), which served as the first level of analysis in the multilevel regression. The biomes as defined by White (1983) were used as the second level of analysis. Mixed models were used to estimate the proportion of different aspects of change in land cover that could be explained by anthropogenic and climatic factors at the landform and biome levels. This hierarchical approach allows the comparison of the different scales at which climate, topography, land-use/land-cover and soil characteristics influence interannual variability in vegetation activity and dynamics.

\section{BACKGROUND}

It has proven to be very difficult to disentangle the effects of climate variability and human land use in remote sensing time series. With the availability of increasing time series of geometrically accurate, atmospherically corrected MODIS data, possibilities to study the interactions between land use and climate factors at the landscape scale have opened up. The MODIS sensors aboard the Terra and Aqua platforms now provide daily global coverage at 250 $\mathrm{m}$ to $1 \mathrm{~km}$ resolution. The improved radiometric and geolocation accuracy of these sensors provides data particularly suited for detailed regional studies of land-cover change (Huete and others 2002).

Most studies investigating the link between interannual AVHRR-NDVI variability and driving forces of this variability focused on one particular potential correlate. Several studies demonstrated positive correlations between Normalized Difference Vegetation Index (NDVI) anomalies and ENSO events in East Africa (for example, Anyamba and Eastman 1996; Myneni and others 1996; Nicholson and Kim 1997; Anyamba and others 2002). Davenport and Nicholson (1993) analyzed annual integrated NDVI-rainfall associations for ten vegetation formations in East Africa and found a strong similarity between temporal and spatial patterns of NDVI when annual rainfall is below about $1,000 \mathrm{~mm}$ and monthly rainfall does not exceed approximately $200 \mathrm{~mm}$. In this range, NDVI was found to be a sensitive indicator of the interannual variability of rainfall. However, Eklundh (1998) cautions that the correlations between AVHRR-NDVI and rainfall become much weaker when one looks at monthly or 10 day time scales. On average, only $10 \%$ of the variation in 10-day NDVI values could be explained by concurrent and preceding rainfall, and up to $36 \%$ for monthly data. Vanacker and others (2005) linked rainfall variability to short-term land-cover change derived from MODIS time series and found that indices of rainfall variability (total annual rainfall and change in rainfall seasonality) were positively related to the magnitude of land-cover change. Physiognomic vegetation types were found to react in specific and distinct ways to short-term fluctuations in rainfall, with grasslands and shrublands being particularly sensitive to short-term rainfall variability, and forest and woodlands being more resilient.

Another body of work investigated the impact of agricultural land use, fire and conservation on ecosystem functioning. Annual profiles, seasonality and interannual variability in integrated AVHRR-NDVI have been studied for areas under agriculture (small 
grain crops, row crops and irrigation) and were compared to profiles for rangelands in North and South America. Agricultural practices reduce the interannual variability of the NDVI signal and change the seasonality of the signal, even if the annual integrated NDVI (iNDVI) for crops and rangelands remains comparable (Guershman and Paruelo 2005; Paruelo and others 2001). Eva and Lambin (2000) linked fire activity to land-cover changes in different ecosystems in Africa and South America. They found that fires play different roles within the different components of landscape mosaics and at different times of land-cover change trajectories. The impact of fires on vegetation was found to be mainly controlled by land use. Other studies have shown that fire changes the iNDVI and seasonality of a rangeland for up to two seasons (Wessels and others 2004; Snyman 2004). A comparison of vegetation changes as measured with AVHRR-NDVI times series (1982-1994) for different types of protected areas in Tanzania demonstrated that the protection status of national parks and game reserves had a positive impact on vegetation health compared to baseline unprotected areas. Woody vegetation regenerated over the 13 year period (Pelkey and others 2000).

However, none of these studies looked at the relative importance of different factors of change in the vegetation signal, nor did they take into account the organization of ecosystems at different levels, from the landscape to the region. Studies looked at variability within biomes, but ignored the variability across biomes, whilst both are related, and factors operating at one level of the hierarchy might influence processes at a higher or lower level. Turner and others (2001) define hierarchy in landscape ecology as being a system of interconnections wherein the higher levels of organization constrain the lower levels to various degrees. These levels of organization operate across different spatial and temporal scales, with different processes being more important at different scales. We hypothesize that climate acts at the global to regional scales to determine vegetation patterns and dynamics. At landscape to local scales, topography and land use determine how vegetation reacts to rainfall variability, whilst soil characteristics play this role at even lower levels of the hierarchy. Recognition of the importance of cumulative environmental effects has resulted in increased recognition of the necessity of analyzing ecosystem dynamics at multiple spatial scales. Such analysis requires the definition of a multi-level hierarchy of nested spatial entities for which explicit relationships and interactions can be specified (MacMillan and others 2004).
Multilevel models were developed in the 1980s and found their first applications in the social sciences, which have focused on the effects of the social context on individual behavior (for example, Aitkin and others 1981; Raudenbush and Bryk 1986). More recently, multilevel models have found applications in ecology (for example, Pearson and others 2004; Wu and David 2002; Noda 2004) and land-use science (Polsky and Easterling 2001; Hoshino 2001; Pan and Bilsborrow 2005). We have defined spatial entities at two levels of organization: the landform level, nested in the biome level. We investigated the relative importance of climate factors on the one hand, and human impact factors such as land use, fire regime, livestock and human population density, and conservation on the other hand, and estimated the influence of each factor at the landform level but also how they vary at the biome level. For this, we applied a multilevel regression model. Multilevel models operate at more than one level or scale simultaneously. This represents a considerable improvement over the usual single-level models by allowing relationships to vary from place to place, and according to context (Jones 1991).

\section{Study Area}

We focused on East Africa, covering Uganda, Kenya, Tanzania, Burundi, Rwanda, southern Sudan, and eastern Democratic Republic of Congo $\left(28^{\circ} 04^{\prime} \mathrm{E}-43^{\circ} 46^{\prime} \mathrm{E} ; 5^{\circ} 55^{\prime} \mathrm{N}-12^{\circ} 38^{\prime} \mathrm{S}\right.$, Figure 1). The area straddles the equator, covers a wide range of vegetation types and is characterized by high interannual variability in rainfall and vegetation activity. The region has a complex climate pattern, with unimodal and bimodal rainfall distributions occurring in different parts of the study area. Rainfall variability is high, with average annual rainfall varying between 240 and $2,340 \mathrm{~mm}$ per year throughout the study area. Topography varies considerably from vast plains areas to steep slopes on the flanks of the highest mountains on the African continent (Mt. Kilimanjaro, Mt. Kenya and Mt. Elgon). It is one of the few regions in Africa for which recent, consistent and reliable land-cover/ land-use data are available at a fine spatial resolution through the Africover project (FAO 2002).

\section{DAtA}

\section{Land-cover Change Indices}

For this study, we used MODIS collection 4 Nadir Bidirectionally Adjusted Reflectance (NBAR) 


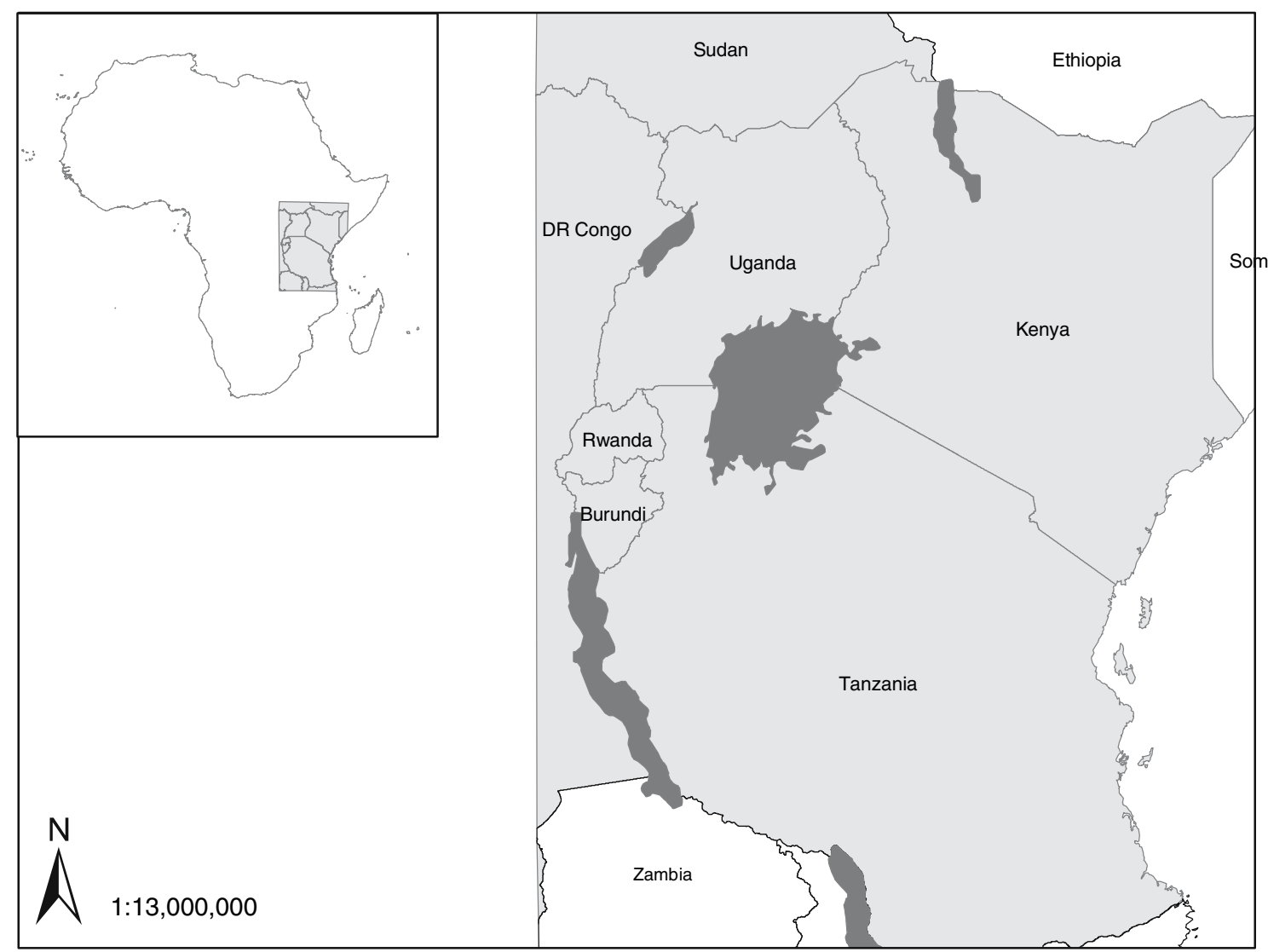

Figure 1. Study area $(1: 13,000,000)$.

visible bands (MOD43B4 product) for East Africa from February 2000 until April 2004. From the NBAR values we computed the Enhanced Vegetation Index (EVI) values for each 16 day period (Linderman and others 2005). EVI is a spectral index similar to the widely used NDVI. Like NDVI, EVI is sensitive to vegetation characteristics such as chlorophyll activity, the fraction of absorbed photosynthetically active radiation, leaf area index (LAI), canopy type and plant physiognomy (Huete and others 2002). A conservative mask was used excluding cloud, noise and pixels with unreliable BRDF correction, which generally removed pixels from analysis in regions consistently clouded such as coastal areas of East Africa (Linderman and others 2005). Calendar years do not typically correspond to the growing seasons. Therefore, to compare annual changes in seasonal vegetation activity, the start of the time series for each pixel was defined based on the midpoint between the start of all growing seasons and end of the previous growing seasons. This provided a 3 year data set with each pixel adjusted to the chosen start of the year. A reference year, defined as the median value of the three yearly EVI values for each period, was extracted from the three full years for each pixel, to provide a baseline of vegetation activity relative to the time period studied. Comparing data for a given year to a reference year is akin to removing the annual cycle and examining anomalies from mean conditions. Three years is a short period, but is used here as a sample to represent patterns of interannual variability in land-cover conditions for a range of ecosystems.

Three indices were developed to measure differences for each pixel between the annual profile for a given year and that of the reference year. The sum of the absolute values of the change vector (SCV) provides a linear measure of the combined changes due to differences in the phenology and/or annual integrated vegetation index (iEVI) compared to the reference year, where $n$ is the number of time steps $i$ in year 1 and $I$ is the vegetation index value at each given time step. The calculation is conducted for year pairs, with 1 the reference year and 2 the off year. 


$$
\mathrm{SCV}=\sum_{i=1}^{n}\left|\left(I_{2}-I_{1}\right)_{i}\right|
$$

Changes due only to differences in the annual iEVI are measured using the absolute difference in the integrated vegetation indices (DIV). Changes in iEVI can be the result of changes in the length of the growing season and/or in the magnitude of within-season EVI.

$$
\mathrm{DIV}=\left|\left[\sum_{i=1}^{n}\left(I_{2}\right)_{i}-\sum_{i=1}^{n}\left(I_{1}\right)_{i}\right]\right|
$$

The seasonal shift index (SSI) measures differences in phenology such as shifts in the start or end of the growing season or in the timing of EVI response within the season that do not affect the differences in the annual iEVI.

$$
\mathrm{SSI}=\mathrm{SCV}-\mathrm{DIV}
$$

The change for a given pixel was expressed as the SCV (or DIV, SSI) divided by the integrated vegetation index of the reference year for that pixel (\%SCV, \%DIV, \%SSI). For a thorough description of the methodological issues concerning the development of the change indices, we refer to Linderman and others (2005). Below, when using "land-cover change", we refer to both trends and interannual variability, and both land-cover conversions and modifications (Lambin and others 2003).

\section{Landforms}

Because most of our independent variables have been collected at a coarser scale than that of the change indices $\left(1 \mathrm{~km}^{2}\right)$, all data were aggregated to the first level of our analysis. We chose areas with similar pedomorphological characteristics as the first level for our analyses, which we refer to hereafter as landforms. This level captures landscape-scale processes. The units were derived from the general soil constraints map for Africa, produced by the global agro-ecological assessment (Fischer and others 2000). This map regroups areas with similar characteristics based on slope, soil fertility, soil texture, soil depth, drainage and chemical constraints. Seven landform types were identified in the study area. The size of the landforms varies considerably across the region, with an average of $957 \mathrm{~km}^{2}$. The landform level is nested within the biome level. We find similar landforms reappearing in different biomes. Landforms, therefore, represent the variability in bio-
Table 1. Vegetation Types in the Study Area (White 1983)

\begin{tabular}{lll}
\hline Vegetation type & Surface $\left(\mathrm{km}^{2}\right)$ & $\%$ \\
\hline Altimontane & 1788 & 0.1 \\
Azonal vegetation & 6964 & 0.4 \\
Bushland and thicket & 537,524 & 32.3 \\
Bushland and thicket mosaics & 118,754 & 7.1 \\
Woodland & 466,099 & 28.0 \\
Woodland mosaics and transitions & 29,134 & 1.7 \\
Forest & 52,176 & 3.1 \\
Forest transitions and mosaics & 316,464 & 19.0 \\
Grassland & 20,854 & 1.1 \\
Edaphic grassland mosaics & 33,877 & 1.7 \\
Semi-desert vegetation & 105,583 & 5.4
\end{tabular}

physical characteristics at the landscape level, whereas the second level of analysis, biomes discussed below, represents these characteristics at a regional level.

\section{Biomes}

For the stratification of the data according to biome type, the UNESCO vegetation map of Africa produced by White (1983) was used. The vegetation classification used is the UNESCO standard based on physiognomy and floristic composition (not climate), and it includes a total of 80 major vegetation types and mosaics. The classification is particularly relevant to this study and has already been used in previous studies of vegetation response to rainfall in Africa (Justice and others 1986; Nicholson and others 1990; Vanacker and others 2005; Linderman and others 2005). Our East African study area is characterized by 11 vegetation types (hereafter referred to as biomes), of which 9 cover more than $1 \%$ of the region (Table 1). These nine biomes were used as the second level of analysis in our multilevel approach.

\section{Land Use}

Land use was derived from the Africover land-cover map for East Africa (FAO 2002). This map was developed through visual interpretation of LandsatTM satellite images and classification based on the Land Cover Classification System (LCCS) methodology (Di Gregorio and Jansen 2000). The landcover maps have all been validated with fieldwork and have been georeferenced to a common standard. The Africover map for East Africa consists of 50 land-cover classes. These were aggregated into the main land-use classes of intensive herbaceous 
agriculture (continuous fields), subsistence herbaceous agriculture (scattered fields with cultivation representing $20 \%$ or more of the surface), intensive tree and shrub crops and plantations, scattered tree and shrub crops, rangelands for intensive grazing (grasslands and savannah) and rangelands for extensive grazing (shrublands), woodlands, forests, marginal lands (bare soil and sparsely vegetated areas) and a miscellaneous class that consisted of built up areas, water bodies and snow, which was masked for the analysis. Swamps were also masked for the analysis, as the reflectance of the water often interferes with the vegetation signal, leading to unreliable change indices. The polygon coverage ( $1 /$ $200,000)$ was gridded to a resolution of $1 \mathrm{~km}^{2}$ and the percent coverage for each land-use type was calculated at the landform level.

\section{Rainfall}

Ten-day rainfall estimates for Africa are processed by NOAA's Climate Prediction Center for the United States Agency for International Development (USAID) Famine Early Warning System (FEWS) to assist in the drought and flood monitoring efforts for the African continent (http://www. igskmncnwb015.cr.usgs.gov/adds/index.php). The rainfall estimates are generated using, among other data sources, Meteosat 7 satellite infrared data, Global Telecommunication System (GTS) data and cloud top temperature data (Xie and Arkin 1996; Herman and others 1997). As it was done with EVI data, annual time series of rainfall data were defined in such a way that they were centred on the rainy season for each pixel. The start of the rainfall year, as opposed to the onset of the rainfall season, was defined for each pixel as the midpoint between the start of the rainfall season and the end of the previous rainfall season (Linderman and others 2005). As the change indices were based on three full years of data with the same start of the year for a given pixel, the start of the rainfall year for a pixel is not necessarily the same as the start of the EVI profile for that same pixel. Hence, lags in vegetation response to rainfall are taken into account on a pixel by pixel basis. Three indices of rainfall variability for the period 2000-2004 were developed and used in this study. The average total annual precipitation (TAP) was calculated at the biome level. The deviation from the TAP at the landform level (TAPdev) was calculated as the difference between TAP and the mean annual rainfall for the landform. The rainfall variability is the sum of the differences in rainfall for each decade in a given year and the corresponding decade in the reference year, which was calculated as the 10 year average rainfall per decade over the period 1994-2004. The mean of the rainfall variability over 3 years is calculated at the landform level.

\section{Seasonality}

Distributions of uni- and bimodal seasons were based on maps developed by Corbett and others (1995). These authors examined the ratio of precipitation to potential evapotranspiration (P/PE) for each month and identified consecutive months above a minimum ratio of 0.50 . Because much of eastern Africa has a bimodal rainfall pattern, they then identified which of the two seasons had a higher P/PE ratio. The characterization criterion of $\mathrm{P} / \mathrm{PE}$ greater than 0.50 , although arbitrary, is a reasonable indicator of conditions that are approaching climatological suitability for crop production.

\section{Fire Frequency}

To analyze the impact of fires on land cover interannual variability, the 8 day active fire summary products from MODIS data (MOD14A2/MYD 14A2) were used. Fire detection was performed using a contextual algorithm (Giglio and others 2003) that exploits the strong emission of mid-infrared radiation from fires (Dozier 1981; Matson and Dozier 1981). The data were adjusted for the start of the year used in the EVI profiles. The fire frequency index (FFI) was constructed as the sum of all active fires detected in a $7 \times 7$ pixel window over the entire study period of 3 years. The mean FFI was calculated at the landform level.

\section{Human Population Density}

The Gridded Population of the World dataset (CIESIN and others 2005) was used. Gridded Population of the World (GPW), Version 3.0 Beta consists of estimates of human population for the years 1990, 1995, and 2000 by 2.5 arcmin grid cells. A proportional allocation gridding algorithm, utilizing more than 300,000 national and sub-national administrative units, is used to assign population values to grid cells. The map reflects the human population density in 2000, based on new census data, or interpolations of population data that rely on spatial hybrids (Balk and Yetman 2004). The mean population density was calculated at the landform level.

\section{Livestock Density}

Tropical livestock units per $\mathrm{km}^{2}$ (TLU) were calculated based on the combined cattle, sheep and goat density maps (FAO 2005). The "Year 2000 Mat- 
ched Predicted Distributions" at 3 min (approx 5 $\mathrm{km})$ resolution were used. The distributions were derived from the most recently available sub-national livestock survey and census data, using a range of agro-climatic and remotely sensed predictors in multivariate regression models. These distributions are further corrected so that national totals match official FAO national population levels for the year 2000 (FAO 2005).

\section{Protected Areas}

In East Africa, protected areas cover an important part of the territory, and include most vegetation types. Most protected areas are wildernesses, void of human habitation and with minimal human impact. We can expect that interannual variability in land cover in these areas is largely free of human impact (except for controlled burning practices). At the same time, these parks have high densities of wild herbivores, so they are not free from grazing pressure. The protected areas layer was derived from the UNEP-WCMC World Database on Protected Areas (2005). Protected areas that have no or few restrictions on human habitation or human land use (for example, Game Controlled Areas in Tanzania) have not been included in the protected areas map.

\section{Data Pre-processing}

All data described above have been transformed to a sinusoidal projection with normal Sphere and resampled to a nominal resolution of $1 \mathrm{~km}$ (actual resolution of $926.6 \mathrm{~m}$ ). The SCV, DIV and SSI change indices were summed over the 3 years of the study period, to create indices that depict shortterm interannual variability of the vegetation activity and phenology. Both for the dependent and independent variables, the natural log was taken where necessary to normalize the distribution of the data. All variables were aggregated to landform units within each of the biomes. For continuous variables, the mean was calculated. For categorical variables we used the mode. The percent area covered by each land-use type and protected land was calculated. We also calculated the mean annual rainfall per biome, because climate is known to control vegetation cover at a higher level in the hierarchy. All continuous independent variables were standardized to a mean of 0 and a standard deviation of 1 .

\section{MethodS}

We analyzed the sensitivities of the change indices to land use, human and livestock densities, fire,

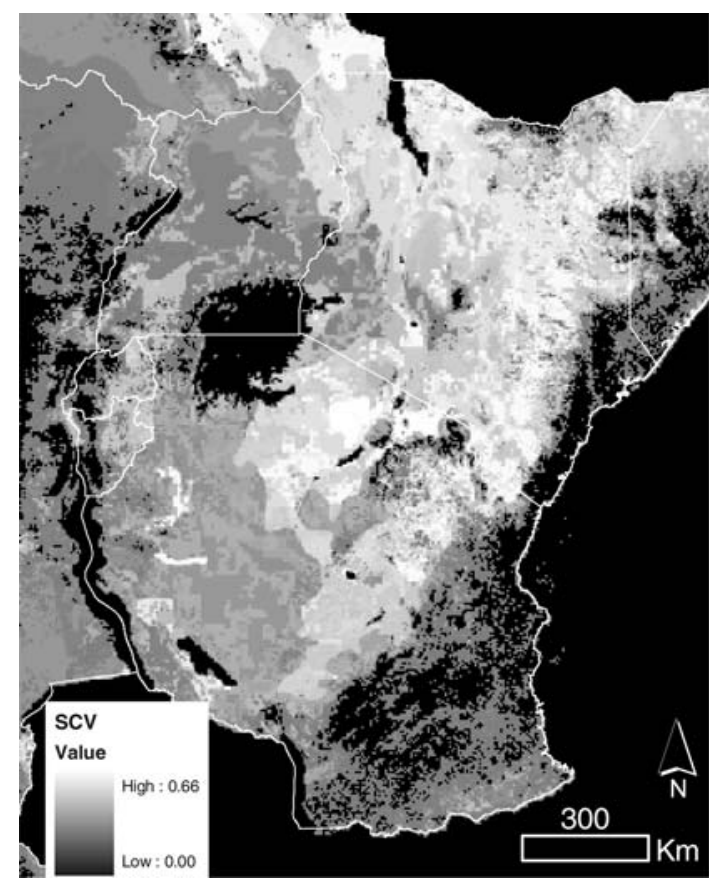

Figure 2. Sum of the absolute values of the Change Vector (SCV) computed from the Enhanced Vegetation Index (EVI) values from the MODIS Nadir Bidirectionally Adjusted Reflectance (NBAR) data for East Africa. The figure represents the summed SCV over the 3 years of the study period (February 2000 to April 2004) aggregated at the landform level.

conservation and climate variability at the landform and biome levels using statistical regression analysis. The dependent variables are percentage change in SCV, DIV and SSI, respectively. We fit a hierarchical model to our data, which is a random coefficients framework modified to account for the issues of scale described earlier. The dependent variable is measured at the landform (lowest) level, and explanatory variables are introduced at both the landform and the biome levels (Hox 2002) (Figures 2-5). Thus, in the hierarchical model, some explanatory variables represent biome-level processes (that is, one average value per biome) whereas other explanatory variables represent landform-level processes (that is, one average value per landform unit within a biome). Actually, overlaying biomes on landforms produced a mosaic of patches of adjacent pixels of the same landform $i$ and biome $j$. The maximum number of patches of type $i j$ is equal to seven landforms multiplied by nine biomes, with a mean patch size of $957 \mathrm{~km}^{2}$. Each patch has similar pedomorphological characteristics and is within one biome. A preliminary analysis of the variance (ANOVA) demonstrated that the mean SCV, SSI and DIV values were sig- 


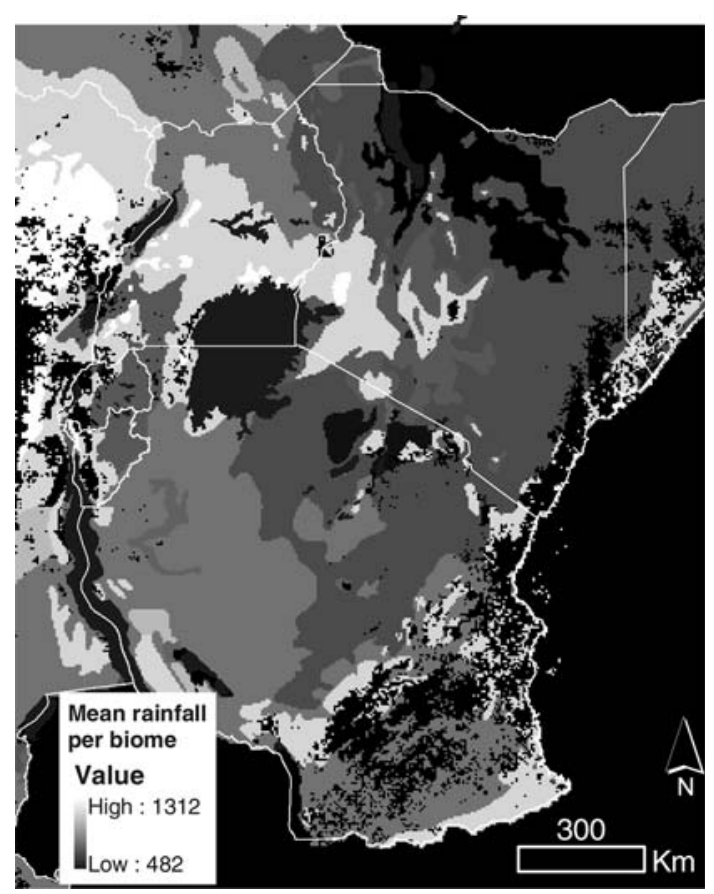

Figure 3. Average total annual precipitation for the period 2000-2004 aggregated at the biome level.

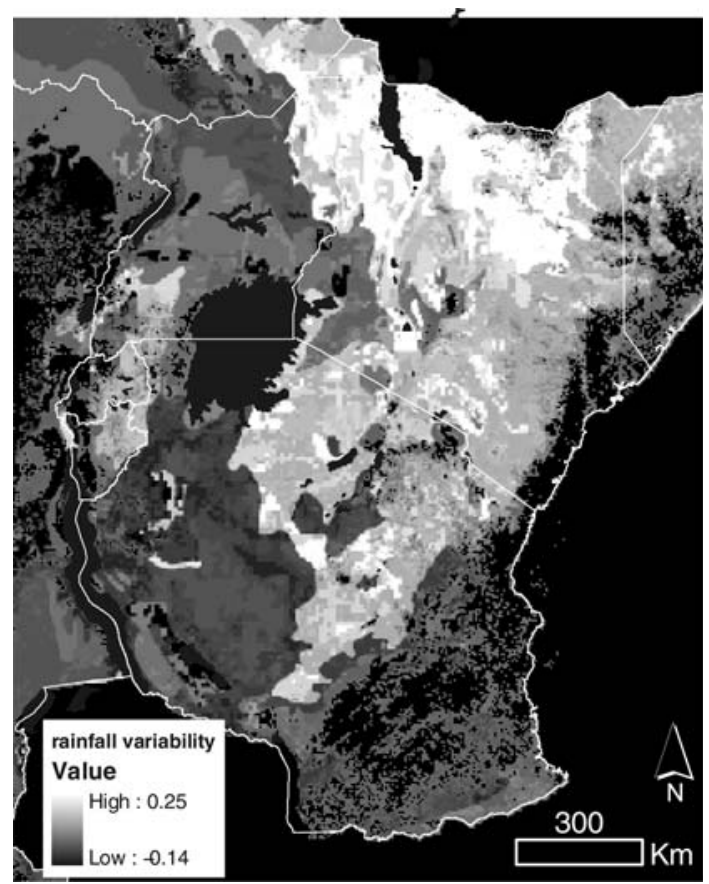

Figure 4. Rainfall variability over 3 years at the landform level, computed as the sum of the differences in rainfall for each decade in a given year and the corresponding decade in the reference year (defined as the 10 year average rainfall per decade over the period 1994 2004).

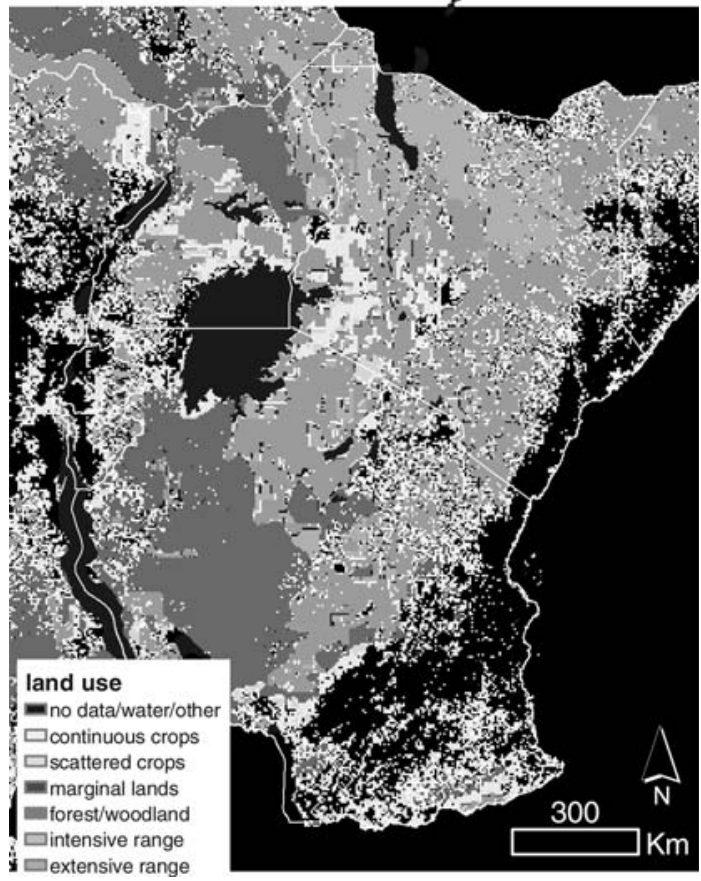

Figure 5. Land use map as derived from the Africover land-cover map for Eastern Africa (FAO 2002) and aggregated at the landform level. For display purpose, only the most frequent land use type per landform unit is represented, and herbaceous and tree/shrub crops have been merged.

nificantly different $(p<0.0001)$ across patches of the same landform $i$ and biome $j$ whether one looks at pixel-level data, or across biomes with data aggregated at the landform level.

A multilevel framework is preferable over the more conventional ordinary least-squares regression (OLS) approach because, with nested data, regression coefficients may exhibit systematic spatial correlations. Spatial dependence means that the data provide less information than if they were distributed at random as is assumed in OLS. Misleading regression results are therefore likely because systematic associations reduce the effective sample size, leading to understated standard error estimates and elevated probabilities of a Type-I error (Snijders and Bosker 1999). A multilevel framework takes into account spatial dependency and thus reduces bias in the results. Full technical details on the models can be found in Snijders and Bosker (1999) and Hox (2002).

In our random coefficients model, landform units are nested within biomes. In this model, both intercepts and slopes are allowed to vary across biomes. In general, biomes with higher intercepts are predicted to have higher values of the depen- 
dent variable (that is, land-cover change) than biomes with low intercepts. Similarly, differences in the slope coefficient for a variable indicate that the relationship between that variable and the dependent variable is not the same in all biomes (Hox 2002). We used the restricted maximum likelihood method (RML) to estimate the fixed and random parts of our models.

An important statistic in OLS is the $R^{2}$, which is interpreted as the proportion of variance modelled by the explanatory variables. In multilevel models, there is variance at different levels, and if there are random slopes, the concept of explained variance has no unique definition (Hox 2002). A straightforward approach to examining the proportion of explained variance consists of examining the residual error variances in a sequence of models. The approximate $R_{1}^{2}$ and $R_{2}^{2}$ estimate the proportion of explained variance at the first and second levels, respectively, for models with random intercepts only.

$$
R_{1}^{2}=\left[\frac{\sigma_{e \mid b}^{2}-\sigma_{e \mid m}^{2}}{\sigma_{e \mid b}^{2}}\right] \text { and } R_{2}^{2}=\left[\frac{\sigma_{u 0 \mid b}^{2}-\sigma_{u 0 \mid m}^{2}}{\sigma_{u 0 \mid b}^{2}}\right]
$$

where $\sigma_{e \mid b}^{2}$ and $\sigma_{u 0 \mid b}^{2}$ are the residual variances for the baseline model and $\sigma_{e \mid m}^{2}$ and $\sigma_{u 0 \mid m}^{2}$ are the residual variances for the comparison model (Hox 2002). The intraclass correlation (ICC) is the proportion of group-level variance compared to the total variance (Hox 2002).

$$
\mathrm{ICC}=\sigma_{u 0}^{2} /\left(\sigma_{u 0}^{2}+\sigma_{e}^{2}\right)
$$

where $\sigma_{u 0}^{2}$ is the highest level residual variance, and $\sigma_{e}^{2}$ is the lowest-level residual variance. The multilevel models were fit using the SAS 9.1.3 proc MIXED algorithm. Preliminary tests for multicollinearity were also conducted in SAS, using the REG procedure.

Multilevel models provide information on both between and within-level variability (random versus fixed effects) related to the means and trends (intercepts and slopes) across multiple hierarchical organization levels (Polsky and Easterling 2001) The first step in the evaluation of multilevel models is to compare an "unconditional" null model without independent variables and fixed intercepts:

$$
\operatorname{LnSCV}_{i j}=\beta_{0 j}+R_{i j}
$$

to a null model with intercepts considered as random effects where the biome-dependent intercept $\beta_{o j}$ is split in an average intercept $\gamma_{o o}$ and the biome-dependent deviation $U_{o j}$ :

$$
\operatorname{LnSCV}_{i j}=\gamma_{00}+U_{0 j}+R_{i j}
$$

The outcome then is essentially an ANOVA partitioning of the total variation into its between $\left(U_{0 j}\right)$ and within-level $\left(R_{i j}\right)$ variability (Polsky and Easterling 2001). The null model likelihood ratio test indicates whether the introduction of random intercepts leads to a significant improvement over the null model consisting of no random effects and a homogeneous residual error.

We then fit a series of models, testing at each step the tenability of the hypothesized scale-based variation. The first model (A) includes landform-level intercept and slope fixed effects only, and this is compared against models including different forms of biome level variation (intercept and slope random effects in models B and C). As above, comparisons between fixed and random effect intercepts compare between and within-group variability whereas differences in random and fixed coefficients examine the difference of betweenand within-group covariate detrending.

The landform model relates landform level values of SCV, DIV or SSI change to the set of $N$ landform-level independent variables $X_{n}$ discussed in the data section, with $n=1, \ldots N$.

$$
\operatorname{LnSCV}_{i j}=\beta_{0 j}+\Sigma \beta_{n j} X_{n i j}+R_{i j}
$$

where $i$ indexes the landforms, $j$ indexes the biomes and $R_{i j}$ is the residual at the landform level. Model A consists only of Eq. (8). Thus, in this model, the unit of observation is the patch of type $i j$. Each biome $j$ is assumed to have a different intercept $\beta_{0 j}$ and slope coefficient $\beta_{n j}$.

Model $\mathrm{B}$ is a random intercepts model, testing that the average change in SCV (or DIV, SSI), given average values of the independent variables, varies between biomes. The model combines Eqs. (8) and (9), where the biome-dependent intercept $\beta_{0 j}$ is split in an average intercept $\gamma_{o o}$ and the biomedependent deviation $U_{O j}$ :

$$
\operatorname{LnSCV}_{i j}=\gamma_{00}+\Sigma \beta_{n j} X_{n i j}+U_{0 j}+R_{i j}
$$

Model C is a random coefficients model, where both the intercepts and the slopes, or regression coefficients, are made biome dependent. Thus, in addition to Eq. (9), the biome-dependent slope $\beta_{n j}$ is also split in an average slope $\gamma_{n o}$ and the biomedependent deviation $U_{n j}$ :

$$
\operatorname{LnSCV}_{i j}=\gamma_{00}+\Sigma \gamma_{n 0} X_{n i j}+U_{0 j}+U_{n j}+R_{i j}
$$

Finally, we introduced biome-level variables $Z_{q}$ (that is, the explanatory variables for which there is 
Table 2. Intraclass Correlation Coefficients for the Null Models

\begin{tabular}{llllll}
\hline & AIC & $\sigma_{e}^{2}$ & $\sigma_{u 0}^{2}$ & ICC & $\chi^{2}$ \\
\hline $\operatorname{lnSCV}$ & 1039 & 0.1152 & 0.1206 & 0.52 & $660 p<0.0001$ \\
lnDIV & 2056 & 0.2314 & 0.1893 & 0.45 & $586 p<0.0001$ \\
lnSSI & 1459 & 0.1543 & 0.06813 & 0.31 & $219 p<0.0001$
\end{tabular}

just one average value per biome and thus represent biome-level processes), so that the full multilevel model D, which combines Eq. (8), (9) and (10) is now extended to (Snijders and Bosker 1999):

$$
\begin{gathered}
\operatorname{LnSCV}_{i j}=\gamma_{00}+\gamma_{10} X_{1 i j}+\cdots+\gamma_{n 0} X_{n i j}+\gamma_{01} Z_{1 j} \\
+\cdots+\gamma_{0 q} Z_{q j}+U_{0 j}+U_{n j}+R_{i j}
\end{gathered}
$$

\section{RESULTS \\ Collinearity}

Before fitting the multi-level model, the possible influence of multi-collinearity needed to be investigated. Strongly interrelated variables can lead to inflated estimates of standard errors, which can lead to unjustified removal of variables from the final analysis (Kleinbaum and others 1998). Although the independent variables were correlated to some degree, the highest variance inflation factor (VIF) was 3.7, and the largest condition index was 8.6, both values remaining well below the warning levels of 10 and 30 for VIF and CI for moderate to severe collinearity (Kleinbaum and others 1998; Woolridge 2000).

\section{Null Model}

The intraclass correlation coefficient (ICC) for the total land-cover change null model was 0.52, indicating substantial spatial clustering at the biome level (Table 2). About half of the total variability in total land-cover change (SCV) values is between biomes and half within the biome (that is, between landforms). The null model likelihood ratio test $\left(\chi^{2}=660, p<0.0001\right)$ indicated a significant improvement over the null model consisting of no random effects and a homogeneous residual error. The change in vegetation productivity (DIV) model had an ICC of $0.45\left(\chi^{2}=586, p<0.0001\right)$. Intraclass correlation for the phenology change (SSI) model was 0.31 , so two thirds of the variability in the data was explained at the landform level of the model, which was considerably higher than for the previous models, but the null model likelihood ratio test still indicated a significant improvement over the null model without random intercepts $\left(\chi^{2}=219, p<0.0001\right)$. This supports our hypothesis that changes in vegetation activity and phenology in East Africa vary considerably between biomes. In all null models, there was a significant amount of unexplained residual variance at the landform and biome levels.

\section{Random Effects}

We first discuss the random effects, followed by the fixed effects for the final model. Our model B focuses on the intercepts. We found that the addition of a random intercept for biomes to the landform level model A significantly improved the model fit. The AIC decreased as compared to model A and the $\chi^{2}$ is $287.9(p<0.0001)$, suggesting significant inter-biome differences in vegetation responses to climate variability (Table 3). Therefore, random intercepts were retained. We further tested for random slopes for the most significant independent variables at the landform level, and found significant random slopes for the rainfall variability variable $\left(\chi^{2}=397, p<0.0001\right)$. We tested for correlation between random slopes and intercepts, but this covariance was not significant.

Finally, to further explain the variation in intercepts at the biome level, we introduced the mean annual rainfall at biome level in the final model D, which led to further model improvement (decreased AIC) compared to model C (Table 3).

Not all biomes had significantly different random intercepts and rainfall variability slopes. Intercept and slope patterns were very similar for the total land-cover change (SCV) and vegetation productivity change (DIV) models. Bushland and grassland biomes had positive intercepts for SCV and DIV models, whereas forest and forest transition biomes had negative intercepts for these models. Hence, the latter two biomes were significantly less susceptible than average to interannual change in total land cover and vegetation productivity, whereas bushland and grassland 
Table 3. Model Fit Statistics for Models with Different Random Component Structures

\begin{tabular}{lccccc}
\hline MODEL & $\begin{array}{l}\text { Null (random } \\
\text { intercept) }\end{array}$ & $\begin{array}{l}\text { A (landform } \\
\text { level variables) }\end{array}$ & $\begin{array}{l}\text { B (landform level } \\
\text { variables + random } \\
\text { intercept) }\end{array}$ & $\begin{array}{l}\text { C (landform level } \\
\text { variables + random level variables + random } \\
\text { intercept \& slope) }\end{array}$ & $\begin{array}{c}\text { D (landform \& biome } \\
\text { intercept } \text { \& slope) }\end{array}$ \\
\hline AIC & 1038.8 & 771 & 485.7 & 398.5 & 389.9 \\
Covariance params & 2 & 1 & 2 & 3 & 3 \\
Chi-square & & & 287.91 & 397 & 129.89 \\
DF & & 1 & 3 & 3 \\
$p$ & & 0.0001 & 0.0001 & 0.0001 \\
\hline
\end{tabular}

Table 4. Total Land-Cover Change Model (SCV), Fixed Effects at Landform and Biome Levels

\begin{tabular}{|c|c|c|c|c|c|}
\hline \multirow{2}{*}{$\begin{array}{l}\text { Model D } \\
\text { Effect }\end{array}$} & \multicolumn{5}{|c|}{ lnSCV model fixed effects } \\
\hline & Estimate & STD & DF & t value & $\operatorname{Pr}>|t|$ \\
\hline Intercept & -1.1139 & 0.03396 & 7 & -32.8 & 0.0001 \\
\hline Protected area & 0.006974 & 0.01069 & 1422 & 0.65 & 0.5142 \\
\hline Ln(livestock density) & 0.004841 & 0.009485 & 1422 & 0.51 & 0.6098 \\
\hline Ln(population density) & -0.01653 & 0.01333 & 1422 & -1.24 & 0.2151 \\
\hline Fire frequency & -0.00013 & 0.01211 & 1422 & -0.01 & 0.9916 \\
\hline Continuous herbaceous crops & 0.02709 & 0.01334 & 1422 & 2.03 & 0.0425 \\
\hline Scattered herbaceous crops & 0.009973 & 0.0102 & 1422 & 0.98 & 0.3284 \\
\hline Continuous tree/shrub crops & -0.0155 & 0.008525 & 1422 & -1.82 & 0.0693 \\
\hline Scattered tree/shrub crops & -0.00721 & 0.007822 & 1422 & -0.92 & 0.3566 \\
\hline Intensive rangelands & 0.08826 & 0.01271 & 1422 & 6.95 & 0.0001 \\
\hline Extensive rangelands & 0.04643 & 0.01223 & 1422 & 3.8 & 0.0002 \\
\hline Forest & -0.04269 & 0.00868 & 1422 & -4.92 & 0.0001 \\
\hline Marginal lands & 0.01898 & 0.008719 & 1422 & 2.18 & 0.0297 \\
\hline Ln(livestock dens.)*int. rangeland & 0.02283 & 0.006997 & 1422 & 3.26 & 0.0011 \\
\hline Ln(livestock dens.)*ext.rangeland & 0.02724 & 0.00908 & 1422 & 3 & 0.0027 \\
\hline Fire frequency*cont. herb. crops & 0.04257 & 0.01706 & 1422 & 2.49 & 0.0127 \\
\hline Fire frequency*int. rangeland & 0.0349 & 0.008115 & 1422 & 4.3 & 0.0001 \\
\hline Fire frequency*ext. rangeland & 0.02919 & 0.008305 & 1422 & 3.52 & 0.0005 \\
\hline Protected area*ext.rangeland & 0.03049 & 0.008019 & 1422 & 3.8 & 0.0001 \\
\hline Protected area*int. rangeland & 0.01335 & 0.007316 & 1422 & 1.83 & 0.0682 \\
\hline Rainfall variability & 0.1032 & 0.04072 & 8 & 2.53 & 0.0351 \\
\hline Deviation from mean biome rainfall & -0.1238 & 0.007723 & 1422 & -16.03 & 0.0001 \\
\hline Mean annual rainfall biome level & -0.1686 & 0.02394 & 1422 & -7.04 & 0.0001 \\
\hline Single season & -0.09779 & 0.01786 & 1422 & -5.47 & 0.0001 \\
\hline Double season & 0 & . & . & . & . \\
\hline
\end{tabular}

biomes showed more than average susceptibility to total land-cover change and changes in vegetation productivity.

\section{Total Land-cover Change: SCV Model}

The fixed effects for the final model (D) are given in Table 4. The introduction of the mean annual rainfall at biome level explained most of the remaining variance at the biome level and further improved the model fit, compared to model C.

We have calculated the approximate $R^{2}$ at the landform and biome levels for several explanatory variables in the random intercepts model (model B). We are fully aware of the limitations of these approximate $R^{2}$ values, especially when random slopes are present in the final model (Snijders and Bosker 1999; Hox 2002). Hence, we just use these 
values as an indication of the explanatory power of different sets of variables, and to compare the relative importance of different independent variables.

The climate variables had the highest explanatory power in the model $\left(R_{2}^{2}=0.33\right.$ and $\left.R_{1}^{2}=0.29\right)$, indicating that about $30 \%$ of the variance at both the landform and biome levels were explained by the climate variables introduced at the landform level. Soil water availability is the key regulator of plant growth in Sub-Saharan Africa, and in these areas, total rainfall amount is a very important indicator of vegetation productivity. Mean annual rainfall contributed significantly at both the landform and the biome levels, leading to significantly different within- and between-group regression coefficients. Up to $83 \%$ of the variance at the biome level was explained by the average rainfall per biome. At both levels, the regression coefficients were negative, hence the larger the amount of annual rainfall, the smaller the total change in land cover will be. Concerning rainfall variability, large deviations from the mean rainfall for an area (positive or negative) were associated with more total change in land cover. However, in bushland and semi-desert biomes, the impact of rainfall variability was attenuated in the random component of the variable, which was negative for both biomes. Woodland transition and edaphic grassland biomes were particularly sensitive to rainfall deviations. Areas with one season showed smaller total changes in land cover than areas with a bimodal rainfall pattern.

Land use was the most important "human" factor influencing the observed total land-cover change (Table 4). On its own, land use explained about $17 \%$ of the variance at the landform level and $48 \%$ of the variance at the biome level. Compared to the average change value for woodlands, which was used as the reference land-use type, total change in land cover increases with increasing proportions of herbaceous agriculture, rangeland and marginal lands. Only forested areas and tree/shrub crops showed less total change in land cover than woodlands. Rangelands had the highest total land-cover change values, with intensively used rangelands showing higher total land-cover change than extensively used ones. Other types of land use had similar total land-cover change characteristics than woodlands. The land use variables also explained a significant amount of the variability at the biome level $(48 \%)$, indicating that land use varies considerably across biomes. Most agriculture can be found in the woodland and forest transition biomes, whereas livestock grazing occurs mainly in the dryer biomes, such as bushland and grassland biomes.

None of the other human impact factors were significant explanatory variables of total land-cover change, but some of them had significant interactions with land-use variables. The impact of livestock densities increases with increasing proportions of rangelands, leading to increased total land-cover change, the effect being more important in extensively used rangelands. Fire was found to have significant interactions with herbaceous agriculture and rangelands. In all cases, increased fire activity in those particular land-use types led to increased total interannual change in land cover. Intensively used rangelands exhibited similar changes in SCV, regardless of their protection status. They are grazed by livestock and/or wildlife. However, changes in SCV were larger for extensively grazed rangelands within protected areas than outside protected areas. The latter could indicate different impacts of wildlife versus livestock grazing.

The multilevel model no longer had significant residual variance at the biome level $\left(\sigma_{u 0}^{2}=0.007193, Z=1.46, p=0.0720\right)$, but part of the variance at the landform level remained unexplained $\quad\left(\sigma_{e}^{2}=0.06640, \quad Z=26.64\right.$, $P<0.0001): R_{1}^{2}=0.42$, thus almost $60 \%$ of the variance at the landform level remained unexplained. Compared to the OLS model (model A), we note that the introduction of the random slopes and intercepts has considerably reduced the contribution of population density, livestock density, protected areas, and fire frequency to the model. The inflation of the importance of these variables in the OLS model was probably due to spatial dependence that has been controlled for in the multilevel model. Re-estimating the full multilevel model after removing the variables that were nonsignificant and had no interaction effect with other explanatory variables did not change the results.

\section{Changes in Vegetation Productivity: DIV Model}

Because the DIV and SSI are components of the SCV change index, we decided to test the same model that was constructed for SCV for these two other change metrics. This will allow for a better understanding of which factors are more associated with interannual change in vegetation productivity as measured by DIV or with variability in phenology (SSI). The random part of the model underwent similar tests as those described above, and resulted in an identical model $\mathrm{D}$, with random 
Table 5. Vegetation Productivity Change Model (DIV): Fixed Effects at Landform and Biome Levels

\begin{tabular}{|c|c|c|c|c|c|}
\hline \multirow{2}{*}{$\begin{array}{l}\text { Model D } \\
\text { Effect }\end{array}$} & \multicolumn{5}{|c|}{ LnDIV model fixed effects } \\
\hline & Estimate & Std Error & DF & $\mathrm{t}$ value & $\operatorname{Pr}>|\mathrm{t}|$ \\
\hline Intercept & -1.8117 & 0.04766 & 7 & -38.01 & 0.0001 \\
\hline Protected area & -0.01824 & 0.01578 & 1421 & -1.16 & 0.248 \\
\hline Ln(livestock density) & 0.02318 & 0.01434 & 1421 & 1.62 & 0.1063 \\
\hline Ln(population density) & -0.02911 & 0.01966 & 1421 & -1.48 & 0.1388 \\
\hline Fire frequency & -0.04325 & 0.01786 & 1421 & -2.42 & 0.0156 \\
\hline Continuous herbaceous crops & 0.04985 & 0.01988 & 1421 & 2.51 & 0.0123 \\
\hline Scattered herbaceous crops & 0.0188 & 0.01507 & 1421 & 1.25 & 0.2124 \\
\hline Continuous tree/shrub crops & 0.007654 & 0.0127 & 1421 & 0.6 & 0.5469 \\
\hline Scattered tree/shrub crops & -0.00513 & 0.01157 & 1421 & -0.44 & 0.6575 \\
\hline Intensive rangelands & 0.1365 & 0.01882 & 1421 & 7.26 & 0.0001 \\
\hline Extensive rangelands & 0.1007 & 0.01818 & 1421 & 5.54 & 0.0001 \\
\hline Forest & -0.03758 & 0.01281 & 1421 & -2.93 & 0.0034 \\
\hline Marginal lands & 0.02302 & 0.01286 & 1421 & 1.79 & 0.0736 \\
\hline Ln(livestock dens.)*int. rangeland & 0.03692 & 0.01077 & 1421 & 3.43 & 0.0006 \\
\hline Ln(livestock dens.)*ext.rangeland & 0.04685 & 0.01377 & 1421 & 3.4 & 0.0007 \\
\hline Fire frequency*cont. herb. crops & 0.05387 & 0.02518 & 1421 & 2.14 & 0.0326 \\
\hline Fire frequency*int. rangeland & 0.03131 & 0.01204 & 1421 & 2.6 & 0.0094 \\
\hline Fire frequency*ext. rangeland & 0.03521 & 0.0123 & 1421 & 2.86 & 0.0043 \\
\hline Protected area*ext. rangeland & 0.01188 & 0.01183 & 1421 & 1 & 0.3156 \\
\hline Protected area*int. rangeland & -0.00596 & 0.0108 & 1421 & -0.55 & 0.5808 \\
\hline Rainfall variability & 0.1123 & 0.06077 & 8 & 1.85 & 0.1019 \\
\hline Deviation from mean biome rainfall & -0.1656 & 0.01144 & 1421 & -14.47 & 0.0001 \\
\hline Mean annual rainfall biome level & -0.2239 & 0.03049 & 1421 & -7.34 & 0.0001 \\
\hline Single season & -0.08965 & 0.02633 & 1421 & -3.41 & 0.0007 \\
\hline Double season & 0 & . & . & . & . \\
\hline
\end{tabular}

intercepts per biome and random slopes for rainfall variability, without covariance between random slopes and intercepts.

Most of the fixed effects had a similar contribution to the vegetation productivity change model (DIV) as to the total land-cover change model (SCV), as can be seen from Table 5. The climate variables had the largest explanatory power in the model at both levels of the hierarchy, explaining $97 \%$ of the variance at the biome level and about $60 \%$ of the variance at the landform level. The sign of the regression coefficients for the rainfall variables was the same as for the total land-cover change model. The average regression coefficient for rainfall variability was no longer significant in the model, but the random slopes for this variable varied significantly between biomes. The coefficients for the mean annual rainfall at the biome level and the deviation from mean biome rainfall were slightly larger in the vegetation productivity change model than in the total land-cover change model, indicating a greater contribution of the rainfall variables to the model of vegetation productivity change.
Land use alone explained about $54 \%$ of the variance at the landform level, and $72 \%$ at the biome level and thus had a higher explanatory power in the vegetation productivity change model than in the SCV model. Intensive herbaceous agriculture showed higher changes in vegetation productivity under average conditions than woodlands (Table 5). Average percentages of rangeland in the landform unit had significantly larger changes in vegetation productivity than woodlands. The only land-use type that showed less change in vegetation productivity was forest. When all human impact variables and interactions were included in the model (without climate variables), we could explain about $60 \%$ of variance at the landform level and $80 \%$ at the biome level.

Higher fire activity had an attenuating effect on vegetation productivity change, but this effect was lessened with increasing proportions of rangeland or herbaceous agriculture at the landform level. Higher livestock densities with increasing proportions of rangeland led to increasing change in vegetation productivity at the landform level. Protection status of the land did not significantly alter 
Table 6. Phenology Change Model (SSI): Fixed Effects at Landform and Biome Levels

\begin{tabular}{|c|c|c|c|c|c|}
\hline \multirow{2}{*}{$\begin{array}{l}\text { Model D } \\
\text { Effect }\end{array}$} & \multicolumn{5}{|c|}{ LnSSI model } \\
\hline & Estimate & Std Error & DF & t value & $\operatorname{Pr}>|\mathbf{t}|$ \\
\hline Intercept & -1.9654 & 0.07811 & 7 & -25.16 & 0.0001 \\
\hline Protected area & 0.03265 & 0.01516 & 1430 & 2.15 & 0.0314 \\
\hline Ln(livestock density) & -0.01652 & 0.01368 & 1430 & -1.21 & 0.2272 \\
\hline Ln(population density) & -0.01311 & 0.01894 & 1430 & -0.69 & 0.4888 \\
\hline Fire frequency & 0.04343 & 0.01694 & 1430 & 2.56 & 0.0105 \\
\hline Continuous herbaceous crops & 0.005997 & 0.01911 & 1430 & 0.31 & 0.7537 \\
\hline Scattered herbaceous crops & 0.001776 & 0.01448 & 1430 & 0.12 & 0.9024 \\
\hline Continuous tree/shrub crops & -0.04091 & 0.01217 & 1430 & -3.36 & 0.0008 \\
\hline Scattered tree/shrub crops & -0.01762 & 0.011 & 1430 & -1.6 & 0.1092 \\
\hline Intensive rangelands & -0.01332 & 0.01775 & 1430 & -0.75 & 0.4529 \\
\hline Extensive rangelands & -0.02947 & 0.0174 & 1430 & -1.69 & 0.0905 \\
\hline Forest & -0.05211 & 0.01218 & 1430 & -4.28 & 0.0001 \\
\hline Marginal lands & 0.002428 & 0.01225 & 1430 & 0.2 & 0.8429 \\
\hline Ln(livestock dens.)*int. rangeland & -0.00146 & 0.01036 & 1430 & -0.14 & 0.888 \\
\hline Ln(livestock dens.)*ext.rangeland & 0.009053 & 0.01309 & 1430 & 0.69 & 0.4893 \\
\hline Fire frequency*cont. herb. crops & 0.03146 & 0.02421 & 1430 & 1.3 & 0.194 \\
\hline Fire frequency*int. rangeland & 0.0419 & 0.01144 & 1430 & 3.66 & 0.0003 \\
\hline Fire frequency*ext. rangeland & 0.01813 & 0.01156 & 1430 & 1.57 & 0.1169 \\
\hline Protected area*ext. rangeland & 0.05525 & 0.01139 & 1430 & 4.85 & 0.0001 \\
\hline Protected area*int. rangeland & 0.03144 & 0.01039 & 1430 & 3.02 & 0.0025 \\
\hline Rainfall variability & 0.02554 & 0.01386 & 1430 & 1.84 & 0.0656 \\
\hline Deviation from mean biome rainfall & -0.06602 & 0.011 & 1430 & -6 & 0.0001 \\
\hline Mean annual rainfall biome level & -0.08191 & 0.06044 & 1430 & -1.36 & 0.1756 \\
\hline Single season & -0.138 & 0.02489 & 1430 & -5.54 & 0.0001 \\
\hline Double season & 0 & . & & . & . \\
\hline
\end{tabular}

the change in vegetation productivity. Neither the parks variable nor its interaction with rangelands was significant in the model.

\section{Changes in Phenology: SSI Model}

The random part of the phenology change model (SSI) was changed in comparison to the total landcover change and vegetation productivity change models, since the random slopes for rainfall variability were no longer significant at the 0.05 level $\left(\sigma_{u 1}^{2}=0.015, Z=1.58, p=0.056\right)$. Hence we only kept random intercepts in the final model, and introduced the biome-level mean annual rainfall to model B.

The fixed part of the model differed considerably from the total land-cover change (SCV) and vegetation productivity change (DIV) models (Table 6). Rainfall variables explained about $28 \%$ of the variance at the biome level and only $4 \%$ of the variance at the landform level. The withinbiome deviation from the mean annual rainfall had the most explanatory power, but the biome- level mean annual rainfall did not contribute significantly to the model. Surprisingly, the common regression coefficient for the rainfall variability was not significant either. There was a marked difference in phenology changes between unimodal and bimodal rainfall areas, with the former having smaller changes in phenology. Land use was not a strong discriminant of phenology change. Most land-use types had similar changes in phenology as the reference class (woodland). Only forests and continuous fields of tree/shrub crops showed markedly less change in phenology than woodlands (Table 6). Total variance explained by land use was about $3 \%$, which is much lower than for the other models. Fire activity generally increased changes in phenology, and more so in intensively used rangeland areas. Phenology change increased with increasing percentages of protected land, and the effect was more important in protected rangelands. The remaining variables did not significantly contribute to intra- and inter-biome variability of vegetation phenology. Residual variance at the 
landform and biome levels remained high in the full multilevel model, so the model probably lacked key explanatory variables.

\section{DisCUSSION}

Our results clearly show that land use contributes significantly to the vegetation response to rainfall variability as measured by time series of MODIS data. Areas with different types of land use react in a different way to interannual climate variability, leading to different values of the change indices depending on the land-use type. Land use modified the interannual variability of vegetation productivity (DIV) and overall change in land cover (SCV), but had little impact on changes in phenology. Land use alone explained more than 50\% of the variance in vegetation productivity changes at the landform level, which was comparable to the explanatory power of the climate variables $(60 \%)$ in that model. Land units under herbaceous crops exhibited more variability in interannual vegetation productivity than woodlands, but less than rangelands under the same climatic conditions (Guershman and others 2003).

Our results indicate that higher livestock densities lead to increasing short-term variability in vegetation productivity and land-cover change in rangelands. Whilst light to moderate grazing generally stimulates plant production (McNaughton and others 1988), Archer (2004) found that some grazing strategies lead to consistently lower longterm vegetation cover measures in the eastern Karoo (South Africa), once rainfall is accounted for. However, the links between livestock densities, rangeland productivity and short-term rainfall variability have not been studied at the landscape to regional level. Although many of the grazing systems in East-Africa are based on grazing on unfenced land by mobile herds, herd mobility is decreasing due to socio-economic and political changes and increasing human population pressure (Oba and others 2000; Homewood 2004). Hence, it becomes more difficult for pastoralists to avoid the adverse effects of droughts by moving animals over long distances to better pastures. In areas with higher livestock densities, decreased herd mobility could aggravate the impact of rainfall variability on vegetation productivity and land-cover change.

The contribution of fire to total land-cover change in rangelands was mainly observed through its impact on phenological changes, much less through changes in vegetation productivity (Eva and Lambin 2000). In the future, we could further improve our understanding of the impact of fire on short-term land-cover change by using burnt area data instead of active fire frequency. This would allow us to take both the frequency and the spatial extent of the fires into account and might lead to much clearer relationships between fire activity and land-cover change for different land-use types (Bucini and Lambin 2002).

Changes in phenology are mainly driven by climate variability and affect most vegetation types in similar ways. Forests and tree/shrub crop plantations showed markedly less interannual variability in phenology (SSI), because those vegetation types typically occur in areas with rainfall levels well above $1,000 \mathrm{~mm} /$ year. At that level, rainfall is no longer a growth limiting factor for vegetation, and interannual variability has less impact on those deeply rooted plants that can easily tap groundwater reserves in times of drought (Davenport and Nicholson 1993). However, none of the climate variables that we used were able to explain an important part of the variance in phenology change at the landform level. The rainfall variability, measuring the decadal deviations from the longterm mean rainfall, captures both changes in timing of rainfall and changes in quantity. An indicator reflecting only changes in timing of rainfall might be better suited to explain short-term changes in vegetation phenology.

Limitations of the study include the short time record. The 3 years analyzed here are used as a sample to represent patterns of interannual variability in land-cover conditions. However, the absence in the study period of a significant La Nina event, which is the largest source of interannual variance in precipitation regimes in this region, makes this short record not fully representative. A longer time record would also be needed to derive implications for livestock keeping and fire use in the region. Similarly, extending the study area would increase the diversity in land cover and land use types and therefore the variance in the interactions between vegetation cover, climate and land use. Another limitation is that land-use heterogeneity was not accounted for at the landform level. Highly fragmented landscapes, with many small patches of different land-use types within a landform are likely to have a different land-cover change signature than landforms consisting of more homogeneous areas of land use. Finally, one should be aware that the analysis presented here does not measure land cover per se but rather surrogates for interannual variability in some land surface conditions derived from moderate resolution remote sensing. The relatively coarse resolution of the data does not allow a full separation of 
processes of land-cover conversion (for example, deforestation, agricultural expansion) and landcover modification (for example, change in rangeland productivity or in species composition).

\section{ConClusion}

In previous studies, it has proven very difficult to disentangle the effects of climate variability and human land use in remote sensing time series. Most studies concentrated on the relationship between climate variability and land-cover change at the pixel level, and looked at changes within biomes, but ignored changes across biomes. Our multilevel approach led to improved models of land cover, vegetation productivity and phenology change and clearly demonstrated that climate influence plays at a different scale than land use and other human use impacts. The factors that have the highest influence on short-term variability in land surface attributes inside and between biomes in the study area were rainfall (mean annual value and variability) and land use. Rainfall patterns affect large areas, and local land use determines how the vegetation cover reacts to the rainfall variability. To understand short-term variability in land cover, we thus need to analyze both climate and land-use patterns, as they both interact and play a role at different spatial scales. Conducting such analyses at the appropriate scales that is, with observations aggregated at the levels corresponding to the different dominant processes influencing land-cover dynamics - has proven to be essential to understand the relative role of multiple driving forces on land surface attributes.

\section{ACKNOWLEDGMENTS}

This work was performed in the FP5's Environment and Sustainable Development Program of the European Commission (CYCLOPES project). We would also like to thank Boston University's MODIS Land Cover group for the provision of the MODIS data, and John D. Corbett (Mud Springs Geographers, Inc.) for the provision of the seasonality data. Antonio Di Gregorio and Craig von Hagen (FAO) kindly provided us with the Africover database for East Africa.We thank Pedram Rowhani for his help with initial image processing, and Sophie Vanwambeke for the advice on multilevel analyses.

\section{REFERENCES}

Aitkin M, Anderson D, Hinde J. 1981. Statistical modelling of data on teaching styles. J R Stat Soc Series A 144:419-61.
Anyamba A, Eastman J R. 1996. Interannual variability of NDVI over Africa and its relation to El Nino/Southern Oscillation. Int J Remote Sensing 17:2533-48.

Anyamba A, Tucker C, Mahoney R. 2002. From El Nino to La Nina: Vegetation response patterns over East and southern Africa during the 1997-2000 period. J Climate 15:3096-103.

Archer ERM. 2004. Beyond the "climate versus grazing" impasse: using remote sensing to investigate the effects of grazing system choice on vegetation cover in the eastern Karoo. J Arid Environ 57:381-408.

Balk D, Yetman G. 2004. The global distribution of population: evaluating the gains in resolution refinement. Working paper.

Bucini G, Lambin E. 2002. Fire impacts on vegetation in Central Africa: a remote-sensing-based statistical analysis. Appl Geol 22:27-48.

Center for International Earth Science Information Network (CIESIN), Columbia University; and Centro Internacional de Agricultura Tropical (CIAT). 2005. Gridded Population of the World Version 3 (GPWv3): Population density grids. Palisades, NY: Socioeconomic Data and Applications Center (SEDAC), Columbia University. Available at http://www.sedac.ciesin.columbia.edu/gpw.

Corbett JD, O`Brien RF, Kruska RJ, Muchugu EI. 1995. Agricultural environments of the Greater Horn of Africa - a database and map set for disaster mitigation. Nairobi: ICRAF.

Davenport M, Nicholson S. 1993. On the relation between rainfall and the normalized difference vegetation index for diverse vegetation types in East-Africa. Int J Remote Sensing 14:2369-89.

Di Gregorio A, Jansen L. 2000. Land Cover Classification System LCCS. Rome: Food and Agriculture Organization of the United Nations.

Dozier J. 1981. A method for satellite identification of surface temperature fields of subpixel resolution. Remote Sensing Environ 11:221-29.

Eklundh L. 1998. Estimating relations between AVHRR NDVI and rainfall in East Africa a 10-day and monthly time scales. Int J Remote Sensing 19:563-68.

Eva H, Lambin E. 2000. Fires and land-cover change in the tropics: a remote sensing analysis at the landscape scale. J Biogeograph 27:765-76.

FAO. 2002. Africover Regional Land Cover Database, http:// www.africover.org.

FAO. 2005. Global Livestock Distributions. Rome: Data Archive produced by Environmental Research Group Oxford Ltd for the Food and Agriculture Organisation of the United Nations.

Fischer G, van Velthuizen H, Shah M, Nachtergaele F. 2000. Global agro-ecological assessment for agriculture in the twenty-first century. Rome: IIASA/FAO.

Giglio L, Descloitres J, Justice CO, Kaufman YJ. 2003. An enhanced contextual fire detection algorithm for MODIS. Remote Sensing Environ 87:273-82.

Guershman J, Paruelo J, Burke I. 2003. Land use impacts on the normalized difference vegetation index in temperate Argentina. Ecol Appl 13:616-28.

Guerschman J, Paruelo J. 2005. Agricultural impacts on ecosystem functioning in temperate areas of North and South America. Global Planetary Change 47:170-80.

Herman A, Kumar V, Arkin P, Kousky J. 1997. Objectively determined 10-day African rainfall estimates created for famine early warning systems. Int J Remote Sensing 18:2 14759. 
Homewood KM. 2004. Policy, environment and development in African rangelands. Environ Sci Policy 7:125-43.

Hoshino S. 2001. Multilevel modeling on farmland distribution in Japan. Land Use Policy 18:75-90.

Hox J. 2002. Multilevel analysis. Mahwah, NJ: Lawrence Erlbaum.

Huete A, Didan K, Miura T, Rodriguez EP, Gao X, Ferreira LG. 2002. Overview of the radiometric and biophysical performance of the MODIS vegetation indices. Remote Sensing Environ 83:195-213.

Jones K. 1991. Multi-level models for geographical research . Norwich: Environmental Publications, University of East Anglia.

Justice CO, Holben B, Gwynne M. 1986. Monitoring East-African vegetation using AVHRR data. Int $\mathrm{J}$ Remote Sensing 7:1453-74.

Kleinbaum D, Kupper L, Muller K, Nizam A. 1998. Applied regression analysis and other multivariate methods. Pacific Grove: Duxbury Press.

Lambin EF, Geist H, Lepers E. 2003. Dynamics of land-use and land-cover change in tropical regions. An Rev Environ Resources 28:205-41.

Linderman M, Rowhani P, Benz D, Serneels S, Lambin EF. 2005. Land-cover change and vegetation dynamics across Africa. J Geophys Res-Atmospheres, 110:D12 AR D12104.

MacMillan M, Jones R, McNabb D. 2004. Defining a hierarchy of spatial entities for environmental analysis and modeling using digital elevation models (DEMs). Computers, Environ Urban Systems 28:175-200.

Matson M, Dozier J. 1981. Identification of subresolution high temperature sources using a thermal IR sensor. Photogram Eng Remote Sensing 47:1311-18.

McNaughton SJ, Ruess RW, Seagle SW. 1988. Large mammals and process dynamics in African ecosystems. BioScience 38:794-800

Myneni RB, Los Tucker SO CJ. 1996. Satellite-based identification of linked vegetation index and sea surface temperature anomaly areas from 1982-1990 for Africa, Australia and South Africa. Geophys Res Lett 23:729-32.

Nicholson S, Davenport M, Malo A. 1990. A comparison of the vegetation response to rainfall in the Sahel and East-Africa, using normalized difference vegetation index from NOAAAVHRR. Climatic Change 17:209-41.

Nicholson S, Kim E. 1997. The relationship of the El Nino Southern oscillation to African rainfall. Int J Climatol 17:11735.

Nicholson SE. 2001. Climatic and environmental change in Africa during the last two centuries. Climate Res 17:123-44.

Noda T. 2004. Spatial hierarchical approach in community ecology: a way beyond high context-dependency and low predictability in local phenomena. Popul Ecol 46:105-17.

Oba G, Stenseth NC, Lusigi WJ. 2000. New perspectives on sustainable grazing management in arid zones of Sub-saharan Africa. BioScience 50:35-51.
Pan W, Bilsborrow R. 2005. The use of a multilevel statistical model to analyze factors influencing land use: a study of the Ecuadorian Amazon. Global Planetary Change 47:232-52.

Paruelo J, Burke I, Lauenroth W. 2001. Land-use impact on ecosystem functioning in eastern Colorado, USA. Global Change Biol 7:631-9.

Pearson R, Dawson T, Liu C. 2004. Modelling species distributions in Britain: a hierarchical integration of climate and landcover data. Ecography 27:285-98.

Pelkey NW, Stone CJ, Caro TM. 2000. Vegetation in Tanzania: Assessing long term trends and effects of protection using satellite imagery. Biol Conserv 94:297-309.

Plisnier P, Serneels S, Lambin EF. 2000. Impact of ENSO on East African ecosystems: a multivariate analysis based on climate and remote sensing data. Global Ecol Biogeography 9:481-97.

Polsky C, Easterling W. 2001. Adaptation to climate variability and change in the US Great Plains: A multi-scale analysis of Ricardian climate sensitivities. Ag Ecosys Environ 85:133-44.

Raudenbush S, Bryk A. 1986. A hierarchical model for studying school effects. Sociol Educat 59:1-17.

Schaaf C, Gao F, Strahler A, Lucht W, Li X, Tsang T, Strugnell N, Zhang X, Jin Y, Muller J, Lewis P, Barnsley M, Hobson P, Disney M, Roberts G, Dunderdale M, Doll C, d`Entremont R, Hu B, Liang S. 2002. First operational BRDF, albedo nadir reflectance products from MODIS. Remote Sensing Environ 83:135-48.

Snijders T, Bosker R. 1999. Multilevel analysis. London: Sage P.

Snyman H. 2004. Estimating the short-term impact of fire on rangeland productivity in a semi-arid climate of South-Africa. J Arid Environ 59:685-97.

Turner MG, Gardner R, O`Neill R. 2001. Landscape ecology. In: Theory and practice. New York: Springer-Verlag.

UNEP-WCMC. 2005. World database on protected areas. http:// www.sea.unep-wcmc.org/wdbpa/.

Vanacker V, Linderman M, Lupo F, Flasse S, Lambin EF. 2005. Impact of short-term rainfall fluctuation on interannual land cover change in sub-Saharan Africa. Global Ecol Biogeography 14:123-35.

Wessels K, Prince S, Frost P, van Zyl D. 2004. Assessing the effects of human-induced land degradation in the former homelands of northern South Africa with a $1 \mathrm{~km}$ AVHRR NDVI time-series. Remote Sens Environ 91:47-67.

White F. 1983. The vegetation of Africa. A descriptive memoir to accompany the UNESCO-AETFAT-UNSO vegetation map of Africa. Paris: UNESCO.

Wooldridge JM. 2000. Introductory econometrics. South Western: A modern approach.

Wu J, David J. 2002. A spatially explicit hierarchical approach to modeling complex ecological systems: theory and applications. Ecol Model 153:7-26.

Xie P, Arkin P. 1996. Analyses of global monthly precipitation using gauge observations, satellite estimates, and numerical model predictions. J Climate 9:840-58. 